This work was generously supported by grants from SandozStiftung zur Förderung der medizinisch-biologischen Wissenschaften, Sandoz AG, Emil Barell-Stiftung, F Hoffmann-La Roche and Co AG, the Juvenile Diabetes Foundation (grant No 80R058), and the Swiss National Science Foundation (3.112-0.81).

Correspondence should be addressed to: Dr I Sklenar, Institute for Microbiology and Hygiene, University of Basel, Petersplatz 10, 4003 Basel, Switzerland.

\section{References}

1 Schernthaner G, Mayr WR. Insulin antibody formation following conventional or monocomponent insulin treatment is influenced by genes of the HLA-DR locus. In: Keck K, Erb P, eds. Basic and clinical aspects of immunity to insulin. Berlin: De Gruyter Co, 1981:263-74.

2 Bertrams J, Grüneklee D. HLA-DR association of humoral immuno- responsiveness to insulin in insulin-dependent (type 1) diabetes mellitus. In: Keck K, Erb P, eds. Basic and clinical aspects of immunity to insulin. 으 Berlin: De Gruyter Co, $1981: 253-61$.

3 Werblin TP, Siskind GW. Distribution of antibody affinities: technique $\widehat{\widehat{\Omega}}$ of measurement. Immunochemistry 1972;9:987-1011.

4 Garotta G, Neri TM. HLA-DR typing by complement-dependent B lymphocyte lysis. In: Immunological methods. Vol 2. New York: 霖
Academic Press Inc, 1981:163-85.

5 Gerbitz KD, Kemmler W. Method of rapid quantitation and characteriza- Tn tion of insulin antibodies. Clin Chem 1978;24:890-4.

- Hudson L, Hay FC. Determination of antibody affinity. In: Practical $\rightleftarrows$ immunology. Oxford: Blackwell Scientific Publications, 1980:98-105.

7 Andersen OO. Anti-insulin-antibodies and late diabetic complications. $\bar{D}$ Acta Endocrinol (Kbh) 1976;83:329-40.

${ }^{8}$ Dornan TL, Ting A, McPherson CK, et al. Genetic susceptibility to the development of retinopathy in insulin-dependent diabetics. Diabetes $1982 ; 31: 226-31$.

(Accepted 24 August 1982)

\title{
Decreased plasma motilin concentrations in pregnancy
}

\author{
N D CHRISTOFIDES，M A GHATEI，S R BLOOM，C BORBERG，M D G GILLMER
}

\begin{abstract}
Plasma motilin concentrations were measured in 37 women during the second and third trimester of pregnancy and one week after delivery. The mean plasma motilin concentrations, both fasting and after a glucose load and a mixed meal, were significantly $(p<0.001)$ reduced during pregnancy, returning to the normal range one week post partum. Pregnancy appears to have a profound inhibitory effect on plasma motilin, and this may in part be responsible for the gastrointestinal hypomotility associated with pregnancy.
\end{abstract}

\section{Introduction}

There has been considerable interest recently in the effect of pregnancy on gastrointestinal motility. ${ }^{1-3}$ Clinical observations such as heartburn, constipation, and gall bladder stasis have been variably attributed to the muscle-relaxing effects of progesterone and the physical impediment of the uterus. Progesterone reduces lower oesophageal sphincter pressure and gastrointestinal motility and also delays gall bladder emptying. ${ }^{4-6}$ It is still not certain, however, whether these effects are direct or mediated via the action of a gastrointestinal hormone.

Motilin is a hormonal peptide ${ }^{7}$ that has gastrointestinal smooth-muscle stimulating effects. Its target organs include the lower oesophageal sphincter, ${ }^{8}$ the stomach, ${ }^{910}$ small $^{11} 12$ and large intestine, ${ }^{13}$ and the gall bladder. ${ }^{14}{ }^{15}$ We investigated the possibility that motilin secretion is altered in pregnancy.

Department of Medicine, Royal Postgraduate Medical School, London W12 0HS

N D CHRISTOFIDES, PHD, senior research officer

M A GHATEI, MPHIL, research officer

S R BLOOM, MD, MRCP, reader

Department of Obstetrics and Gynaecology, St Mary's Hospital Medical School, London W2 1PG

C BORBERG, MD, research fellow

M D G GILLMER, MD, MRCOG, lecturer (now: clinical reader, Nuffield

Department of Obstetrics and Gynaecology, John Radcliffe Hospital, Oxford OX3 9DU)

\section{Subjects and methods}

Three groups of patients were recruited before 16 weeks' gestation to study the effect of maternal adiposity on glucose tolerance during pregnancy. ${ }^{16} \mathrm{~A}$ total of 37 subjects were studied, nine whose weight $\bar{\sigma}$ was less than $80 \%$ of their ideal body weight, 10 whose weight was $\underline{-}$ between 90 and $110 \%$ of their ideal body weight, and 18 with a weight $\overrightarrow{.}$ greater than $120 \%$ of ideal body weight. These women were studied $œ$ at 16 and 36 weeks of pregnancy and one week post partum. After ? an overnight fast the subjects were given a conventional three-hour 50-g oral glucose tolerance test and half-hourly blood samples were $\sum^{2}$ taken via an indwelling intravenous cannula. After this the subjects were given a mixed meal of about $2.09 \mathrm{MJ}$ (500 calories), containing $40 \%$ fat, $40 \%$ carbohydrate, and $20 \%$ protein, and further half-hourly blood samples were taken over a period of three hours. The blood $\varrho$ samples were centrifuged immediately and the plasma stored at $-20^{\circ} \mathrm{C} . \overrightarrow{\vec{O}}$

Details of the plasma motilin radioimmunoassay used have been 3 published. ${ }^{7}$ The antibody used (M1) does not crossreact with any of the known gut hormones, and appears to be $N$-terminal specific. This assay can detect changes in plasma motilin of $3 \mathrm{pmol} / 1$ with $95 \%$ confidence. To avoid interassay variation, all the samples in the present study were estimated in one assay (intra-assay variation was $5 \%)$. The mean fasting motilin concentration $( \pm$ SEM) observed in $\overline{0}$ normal non-pregnant subjects in this laboratory is $48 \pm 6 \mathrm{pmol} / \mathrm{l}^{7}$

The research protocol was approved by the ethics committee of $\dot{\delta}$ St Mary's Hospital and informed consent was obtained from each 3 subject before the study.

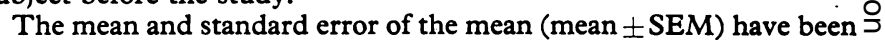
used throughout. The Wilcoxon signed rank test was used to test for $N$ differences in the motilin concentrations at 16 and 36 weeks of $D$ pregnancy and post partum. The mean of the values obtained 30 음 minutes before and immediately before the glucose load have been taken as the mean fasting value. The mean of the values 150 and $180 \mathrm{O}$ minutes after the glucose load have been taken as the "basal" value ${ }^{N}$ before the meal.

\section{Results}

There was no difference in the plasma motilin concentrations in the groups studied and no correlation between body weight and motilin $\bigcirc$ concentrations; the data from the three groups have therefore been $\mathbb{D}$ pooled.

The figure shows the results obtained. The mean fasting plasma motilin concentration at 16 weeks of pregnancy was $23 \pm 2.8 \mathrm{pmol} / 10$ (median 20, range 5-91 pmol/1). This was not significantly different? from the concentration at 36 weeks of pregnancy $\left(21 \pm 2.5 \mathrm{pmol} / \mathrm{l}_{x} \mathrm{0}\right.$. median 17, range 4-58 pmol/1). The concentration one week after $\rightleftharpoons$ 
delivery $(57 \pm 4.9 \mathrm{pmol} / \mathrm{l}$, median 51 , range $18-134 \mathrm{pmol} / \mathrm{l})$ was, however, significantly higher than that observed during pregnancy in the same subjects $(p<0.001)$ and was in the normal range for nonpregnant women.



Plasma motilin concentrations (pmol/l) (mean \pm SEM) in 37 women at 16 weeks of pregnancy (solid dots), 36 weeks of pregnancy (open circles), and one week post partum (squares). The $50 \mathrm{~g}$ glucose load was given at 0 minutes and the meal at 180 minutes.

Plasma motilin concentrations fell after the glucose load. The mean value 150 minutes after glucose was $17 \pm 2 \cdot 2 \mathrm{pmol} / 1$ at 16 weeks of pregnancy and $16 \pm 2.0 \mathrm{pmol} / 1$ at 36 weeks; both these values were significantly below that observed one week post partum (38 \pm 3.9 $\mathrm{pmol} / \mathrm{1} ; \mathrm{p}<0.001$ ).

Plasma motilin concentrations rose after ingestion of the mixed meal. The postprandial plasma motilin rise 30 minutes after ingestion of the meal was $10.3 \pm 1.3 \mathrm{pmol} / 1$ at 16 weeks and this was lower than that at 36 weeks $(15.6 \pm 1.9 \mathrm{pmol} / \mathrm{l} ; \mathrm{p}<0.01)$. These rises were both smaller than that observed one week post partum $(23.0 \pm 3.1 \mathrm{pmol} / \mathrm{l}$; $\mathrm{p}<0.001)$.

\section{Discussion}

Motilin is a gastrointestinal hormone that has recently been isolated and is thought to be one of the factors controlling gastrointestinal motility. ${ }^{7}$ Intravenous infusions of this hormone adjusted to produce a rise in plasma motilin concentrations which lie within the physiological range have been shown to greatly accelerate gastric emptying, ${ }^{917}$ to stimulate the lower oesophageal sphincter, ${ }^{8}$ and to reduce intestinal transit time. ${ }^{18}$ Other actions of motilin include stimulation of the electrical and mechanical activities of the small bowel ${ }^{11}{ }^{12}$ and colon ${ }^{13}$ and emptying of the gall bladder. ${ }^{14} 15$

The mean basal motilin concentration observed a week after delivery in the women studied was similar to that reported by the authors in non-pregnant controls ${ }^{7}$ but there was a significant suppression of basal values during early and late pregnancy. The decline in plasma motilin concentrations observed after the oral glucose load and the increase after the mixed meal, which is thought to be due to fat, ${ }^{19}$ are in keeping with previous findings in non-pregnant subjects, ${ }^{19}$ but the magnitude of the changes observed during pregnancy was less than those previously reported.

It is generally held that pregnancy is associated with some degree of gastric atony and bowel hypomotility. ${ }^{1-3}$ Although the exact cause of this is unknown, recent evidence suggests that progesterone and other steroid hormones may be responsible. ${ }^{18-520}$ Progesterone exposure is associated with a reduction of lower oesophageal sphincter pressure ${ }^{4}$ and a delay in gastrointestinal transit time ${ }^{20}$ and gall bladder emptying ${ }^{317}$ during the luteal phase of the menstrual cycle. The evidence accumulated thus far does not, however, exclude the possibility that progesterone may cause stimulation of an inhibitory gastrointestinal hormone or the inhibition of a stimulatory hormone. The results presented here are consistent with the latter hypothesis as they show significant suppression of both basal plasma motilin concentrations and those observed after a meal during pregnancy. It is thus possible that low motilin concentrations may contribute towards the gastrointestinal hypomotility of pregnancy.

We thank the Medical Research Council, the Joint Standing Research Committee of St Mary's Hospital Medical School, and Conicit, Venezuela, for generous financial support.

\section{References}

1 Feeney JG. Heartburn in pregnancy. Br Med f 1982;284:1138-9.

2 Hytten FE. The alimentary system. In: Hytten FE, Chamberlain G, eds. Clinical physiology in obstetrics. Oxford: Blackwell Scientific Publications, 1980:1147-62.

${ }^{3}$ Cohen S. The sluggish gall bladder of pregnancy. $N$ Engl $\mathcal{F}$ Med 1980; 302:397-8.

4 Fisher RS, Roberts GS, Grabowski CJ, Cohen S. Inhibition of lower esophageal sphincter circular muscle by female sex hormones. $A m \mathfrak{F}$ Physiol 1978;23:E243-7.

5 Bruce LA, Behsudi FM. Progesterone effects on three regional gastrointestinal tissues. Life Sci 1979;25:729-34.

- Lind JF, Smith AM, McIver DK, et al. Heartburn in pregnancy-a manometric study. Can Med Assoc F 1968;98:571-94.

${ }^{7}$ Christofides ND, Bloom SR. Motilin. In: Bloom SR, Polak JM, eds. Gut hormones, 2nd ed. Edinburgh: Churchill Livingstone, $1981: 272-9$.

8 Lux G, Rosch W, Domschkes, et al. Intravenous 13-Nle-motilin increases the human lower oesophageal sphincter pressure. Scand $\mathcal{f}$ Gastroenterol 1976;11,suppl 39:75-9.

${ }^{9}$ Christofides ND, Modlin IM, Fitzpatrick ML, Bloom SR. Effect of motilin on the rate of gastric emptying and gut hormone release during breakfast. Gastroenterology 1976;76:903-7.

10 Christofides ND, Long RG, Fitzpatrick ML, McGregor GP, Bloom SR. Effect of motilin on the gastric emptying of glucose and fat in humans. Gastroenterology $1981 ; 80: 456-60$.

11 Itoh Z, Honda R, Hiwatashi $\mathrm{K}$, et al. Motilin-induced mechanical activity in the canine alimentary tract. Scand F Gastroenterol 1976;11,suppl 39: 93-110.

12 Vantrappen G, Janssens J, Peeters TL, Bloom SR, Christofides ND, Hellemans J. Motilin and the interdigestive migrating motor complex in man. Dig Dis Sci 1979;24:497-500.

13 Rennie JA, Christofides ND, Mitchenere P, Johnson AG, Bloom SR. Motilin and human colonic activity. Gastroenterology 1980;78:A1243.

14 Adrian TE, Mitchenere P, Sagor GR, Christofides ND, Bloom SR. Effect of motilin and other gut hormones on gallbladder pressure. Regul Pept 1980;1,suppl:A1.

15 Itoh Z, Takashi I. Periodic contractions of the canine gallbladder during the interdigestive state. Am $\mathcal{F}$ Physiol 1981 ;3 :G183-9.

16 Borberg C, Gillmer MDG, Brunner EJ, et al. Obesity in pregnancy: the effect of dietary advice. Diabetes Care 1980;3:476-81.

17 Nilsson S, Stattin S. Gallbladder emptying during the normal menstrual cycle. Acta Chir Scand 1967;133:648-52.

18 Ruppin H, Sturm G, Westhoff D, et al. Effect of 13-Nle-motilin on small intestinal transit time in healthy subjects. Scand $\mathcal{F}$ Gastroenterol 1976; 11,suppl $39: 85-8$.

19 Christofides ND, Bloom SR, Besterman HS, Adrian TE, Ghatei MA. Release of motilin by oral and intravenous nutrients in man. Gut 1979; 20:102-6.

20 Wald A, Van Thiel DH, Hoechspetter L, et al. Gastrointestinal transit: the effect of the menstrual cycle. Gastroenterology $1981 ; 80: 1497-500$.

(Accepted 14 September 1982)

ONE HUNDRED YEARS AGO Sir Garnet Wolseley is said to have ordered that the troops under his command should be allowed daily a triple ration of tea; and it is stated that the extra issue of tea is very acceptable to the men. A second ration of coffee is also ordered daily for every man. No more tinned meats have been sent to the seat of war, but 300 tons of other provisions have been despatched to Ismailia by the steamship Adowa. These include, as an exceptional article for hospital uses, a quantity of preserved tongues. The medical department has also transmitted to the hospitals a number of dry cold air refrigerators. (British Medical fournal, 1882.) 